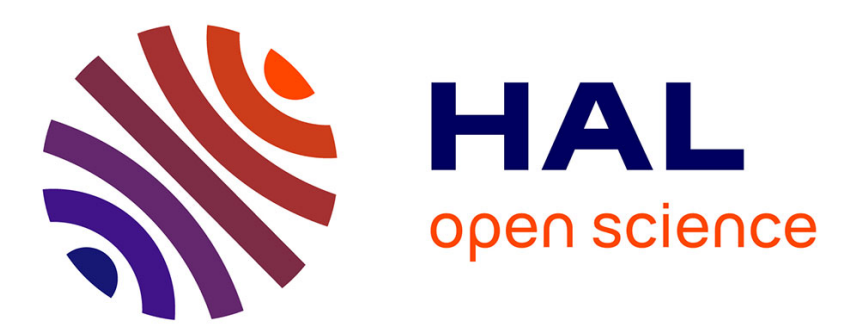

\title{
Hydrolytic kinetic model predicting embrittlement in thermoplastic elastomers
}

Antoine Bardin, Pierre Yves Le Gac, Stéphane Cérantola, Gaëlle Simon, Hervé Bindi, Bruno Fayolle

\section{- To cite this version:}

Antoine Bardin, Pierre Yves Le Gac, Stéphane Cérantola, Gaëlle Simon, Hervé Bindi, et al.. Hydrolytic kinetic model predicting embrittlement in thermoplastic elastomers. Polymer Degradation and Stability, 2020, 171, pp.1-12. 10.1016/j.polymdegradstab.2019.109002 . hal-02529608

\section{HAL Id: hal-02529608 \\ https://hal.science/hal-02529608}

Submitted on 2 Apr 2020

HAL is a multi-disciplinary open access archive for the deposit and dissemination of scientific research documents, whether they are published or not. The documents may come from teaching and research institutions in France or abroad, or from public or private research centers.
L'archive ouverte pluridisciplinaire HAL, est destinée au dépôt et à la diffusion de documents scientifiques de niveau recherche, publiés ou non, émanant des établissements d'enseignement et de recherche français ou étrangers, des laboratoires publics ou privés. 


\title{
Hydrolytic kinetic model predicting embrittlement in thermoplastic elastomers
}

\author{
Antoine Bardin a, c, d, Pierre-Yves Le Gac a, *, Stéphane Cérantola ${ }^{\text {b }}$, Gaëlle Simon ${ }^{\text {b }}$, \\ Hervé Bindi ${ }^{c}$, Bruno Fayolle ${ }^{\mathrm{d}}$ \\ a Marine Structure Laboratory, IFREMER, Centre de Bretagne, 29280, Plouzané, France \\ ${ }^{b}$ Plateforme RMN-RPE, UFR Sciences et Techniques, University of Western Brittany, 6 Av. V. Le Gorgeu CS93837, 29238, Brest Cedex 3, France \\ ' Thales DMS France, 525 route des Dolines, 06560, Valbonne, France \\ d PIMM Laboratory, Arts et Métiers ParisTech, CNRS, Cnam, HESAM Université, 151 boulevard de l'Hôpital, 75013, Paris, France
}

Keywords:

Thermoplastic elastomer

Hydrolysis

Kinetic model

Structure-property relationships

\begin{abstract}
A B S T R A C T
A hydrolytic kinetic model predicting chains scissions of a polyurethane elastomer (TPU) containing an anti-hydrolysis agent (stabilization via carbodiimide) was developed. This model is based on four components: uncatalysed hydrolysis, acid-catalysed hydrolysis, carboxylic acid dissociation and competitive carbodiimide-based deactivation of acid. Protons were considered as the key catalyst responsible for the hydrolysis. Model parameters were determined by fitting experimental data measured on unstabilized and stabilized TPUs, aged in immersion from 40 to $90^{\circ} \mathrm{C}$. Scission kinetics were predicted for immersion and 50\% relative humidity conditions, from 10 to $100{ }^{\circ} \mathrm{C}$. Structure-failure property relationships were also investigated, between molar mass and elongation at break. A master curve was established for elongation at break with molar mass, including both TPUs at four ageing temperatures. By combining predictions for scission kinetics with the molar mass-elongation at break master curve and an embrittlement molar mass as the end-of-life criterion, non-Arrhenian lifetime predictions are proposed for all exposure conditions considered.
\end{abstract}

\section{Introduction}

Since their appearance in the 1960s, thermoplastic elastomers (TPEs) are being increasingly considered for a range of applications including automotive, medical equipment and aeronautics. In particular, linear segmented polyurethane elastomers (TPUs) are potential candidates for replacing thermoset elastomers, as they present similar mechanical properties such as low modulus or elasticity behaviour. Conventional thermoplastic processes such as injection moulding or extrusion are used for these materials. The overall processing of TPEs is thus simpler compared to thermoset elastomers. They also do not require curing systems or reinforcing agents. This point is of importance for industrial use, as regulations are becoming more restrictive towards the use of hazardous chemicals in industrial processes. We can for example cite the REACH regulation concerning the European Union, adopted to improve the protection of human health and environment. In this

\footnotetext{
* Corresponding author.

E-mail address: pierre.yves.le.gac@ifremer.fr (P.-Y. Le Gac).
}

context, TPEs represent a clean alternative solution to vulcanized rubbers.

TPUs are segmented copolymers, composed of alternative covalently bonded hard segments and soft segments. They possess a wide range of mechanical properties, as they are highly tuneable through segment nature, hard/soft segment fraction or molecular weight. Hard segment is commonly composed of an association of short chain diol, also called chain extender, and a diisocyanate. Soft segment is composed of a long diol chain, of diverse natures such as polyether, polyester or polycaprolactone. Studied grades have hard segments composed of methyl diphenyl diisocyanate (MDI) and butanediol (BD), while the soft blocks are polyadipates. They have a large soft segment fraction, hence showing elastomeric properties. Interactions between hard segments, such as hydrogen bonding, lead to physical crosslinking between polymer chains [1]. Polyadipate-based TPUs are known for their good mechanical properties and resistance to oxidative degradation [2,3]. However, water exposure is known to degrade ester-based polymers, mostly through ester group hydrolysis [2,4,5]. From the two functional groups in TPUs most sensitive to hydrolysis, studies showed that 
ester group hydrolysis is faster than urethane hydrolysis by at least an order of magnitude [6-8]. This phenomenon causes molecular chains scissions, observable by molar mass decrease. Acidic products produced during ester hydrolysis cause the autocatalysis of the reaction. Autocatalysis of ester hydrolysis has been particularly studied in the case of bioresorbable materials, for which a good control of degradation kinetics is required $[9,10]$. Anti-hydrolysis agent can be used to delay degradation, when material durability is sought [11-14]. This additive acts as an acid scavenger, inhibiting the hydrolysis catalysis, having a major effect on degradation kinetics.

We focus in this article on understanding the effect of water on TPU-ester structure and mechanical properties. We propose a relevant model predicting mechanical failure property decrease for TPU, independently of exposure temperature. This model is based on an existing one, proposed by Brown et al. [12], which has been extended. In order to validate the model proposed in this paper, chain scission concentration during immersion of unstabilized and stabilized TPUs was assessed. The choice of a TPU having a small amount of anti-hydrolysis agent enabled to dissociate the catalysed and uncatalysed hydrolysis kinetics. Relevant reactions and their kinetic parameters were identified. Temperature influence on these parameters is discussed. Relationships between elongation at break and structural parameters are also investigated, considering that a drop of elongation at break is often associated with polymers end of life. Finally, by combining the chains scissions modelling and relevant structure-fracture property relationship, we propose to build a lifetime prediction over a wide range of temperature.

\section{Materials and methods}

\subsection{Materials}

Covestro supplied the two DESMOPAN"M TPUs studied, in granular form. $1.5 \mathrm{~mm}$-thick plates were produced by injection moulding. Both grades are ester-based TPUs, one containing an anti-hydrolysis agent, and one stabilizer-free. These TPU-ester are synthesized from three raw components, a diisocyanate, a macrodiol and a chain extender, being respectively: 4,4-methylene-bis(phenylisocyanate) (MDI), poly(1,4-butylene adipate) (PBA) and butylene glycol (BDO). Association of MDI and BDO forms hard blocks, while PBA constitutes the soft blocks (Fig. 1). Hard and soft blocks are covalently bonded through urethane group. The synthesized multi-block macromolecules are hydroxyl-terminated. The anti-hydrolysis agent is a monomeric carbodiimide, commercialized as Stabaxol. Several material characteristics, such as the hard block weight ratio $W_{\text {hard }}$ deduced from NMR peaks integration as well as initial molar mass determined by Gel Permeation Chromatography (GPC) are reported in Table 1.

\subsection{Methods}

\subsubsection{Annealing}

In order to thermally stabilize the TPUs, samples were annealed for $15 \mathrm{~h}$ at $100^{\circ} \mathrm{C}$ under vacuum, followed by a slow cooling (oven turned off). DSC analysis performed on annealed samples confirmed a crystalline structure stable up to $100^{\circ} \mathrm{C}$.

\subsubsection{Ageing}

Hydrolytic degradation was induced by immersing samples in tanks filled with continuously renewed water, regulated at four different temperatures between 40 and $90^{\circ} \mathrm{C}$. Samples were removed periodically. Drying during $48 \mathrm{~h}$ at $40^{\circ} \mathrm{C}$ was performed in a desiccator to avoid any further degradation.

\subsubsection{Mass uptake}

Mass uptake of $50 \mathrm{~mm} \times 50 \mathrm{~mm} \times 1.5 \mathrm{~mm}$ samples was followed by periodic weighing on a Sartorius LA $310 \mathrm{~S}$ balance $(0.1 \mathrm{mg}$ precision). Samples were removed from water, wiped with paper towels and weighed. The mass uptake of each sample at time $t$ is expressed as a percentage as Equation (1), with $\mathrm{m}_{0}$ the sample initial mass and $\mathrm{m}(\mathrm{t})$ the sample mass after immersion time $\mathrm{t}$.

Mass uptake $=\frac{m(t)-m_{0}}{m_{0}} \times 100$

\subsubsection{Gel Permeation Chromatography (GPC)}

GPC analyses were performed at $40^{\circ} \mathrm{C}$ using THF as eluent on a Malvern Viscotek TDA apparatus equipped with two Malvern T3000 and T6000 columns with a Malvern refractive index detector at an elution rate of $1 \mathrm{~mL} / \mathrm{min}$. Polystyrene was used as a standard. Number average molar mass $M_{n}$ and mass average molar mass $M_{w}$ were calculated as relative values from this standard. Polydispersity was calculated as $Đ=M_{w} / M_{n}$.

\subsubsection{Nuclear magnetic resonance (NMR)}

One- and two-dimensional NMR spectra were recorded at $25^{\circ} \mathrm{C}$ on a Bruker Avance III HD500 spectrometer (Bruker, Wissemboug, France) equipped with an inverse $5 \mathrm{~mm}$ BBO 1H/BB z-gradient

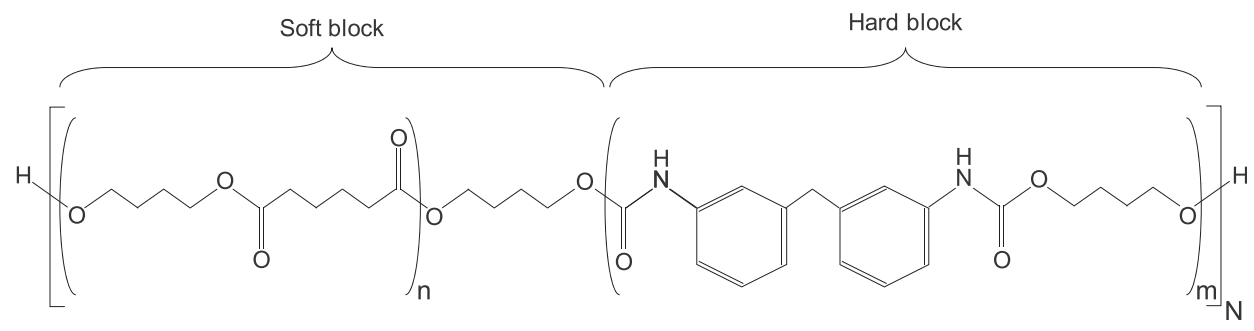

Fig. 1. Ester-based TPU chemical structure.

Table 1

TPUs properties.

\begin{tabular}{|c|c|c|c|c|c|c|}
\hline & Soft block nature & Hard block nature & Hydrolytic stabilizer & Molar Mass $\left(\mathrm{kg} \cdot \mathrm{mol}^{-1}\right)$ & $W_{\text {hard }}$ & Density $\left(\mathrm{g} . \mathrm{cm}^{-3}\right)$ \\
\hline Unstabilized TPU & Polyadipate & $\mathrm{MDI}+\mathrm{BD}$ & No & 68.7 & 0.23 & 1.19 \\
\hline Stabilized TPU & polyadipate & $\mathrm{MDI}+\mathrm{BD}$ & Yes & 84.3 & 0.23 & 1.19 \\
\hline
\end{tabular}


probe head, using standard pulse sequences available in the Bruker software. Chemical shifts are expressed relative to THF (as internal reference) or TSP (as external reference) for TPU and 1,2 butanediol/ adipate, respectively.

\subsubsection{Differential scanning calorimetry (DSC)}

DSC analyses were performed on Q200 equipment from TA Instruments. Heating scans were performed from 10 to $230^{\circ} \mathrm{C}$ at a rate of $10^{\circ} \mathrm{C} / \mathrm{min}$ under inert atmosphere $\left(\mathrm{N}_{2}\right)$. Sample mass was around $10 \mathrm{mg}$, weighed exactly. Melting enthalpy $\Delta \mathrm{H}_{\mathrm{m}}$ was integrated from endothermic peaks.

\subsubsection{Wide angle X-Ray scattering (WAXS)}

WAXS measurements were performed on the high brilliance SWING beamline at the Soleil Synchrotron facility. The monochromator was set at $12 \mathrm{KeV}$. Diffraction patterns were recorded at room temperature, with a CCD detector at $0.5 \mathrm{~m}$ from the sample. 1D WAXS curves were obtained by circular averaging of 2D images, using Foxtrot software. 10 images were taken for each sample, from which final 1D curve is averaged. Fityk software was used for diffractogramme deconvolution.

\subsubsection{Uniaxial tensile test}

Tensile tests were performed on a $10 \mathrm{kN}$ Instron machine in a room regulated at $21 \pm 1{ }^{\circ} \mathrm{C}$ and $50 \%$ relative humidity, at a rate of $50 \mathrm{~mm} / \mathrm{min}$. Three specimens were tested for each condition. A $500 \mathrm{~N}$ cell was used to measure load and true strain was measured using an in-house video extensometer.

\section{Results}

\subsection{Water absorption}

Water absorption properties were assessed on $50 \mathrm{~mm} \times 50 \mathrm{~mm} \times 1.5 \mathrm{~mm}$ samples at different temperatures from 25 to $80^{\circ} \mathrm{C}$, for unstabilized and stabilized TPUs. Mass uptake by water sorption was followed until saturation was reached. Fig. 2 shows the mass uptake for both TPUs. Water uptake can be described with a Fickian law for unstabilized and stabilized TPUs, represented in dashed lines.

Considering samples as thin sheets (thickness « width and length), a 1D Fickian model was applied to determine the diffusion coefficient D according to Equation (2).

$\frac{d C}{d t}=D \frac{d^{2} C}{d x^{2}}$ with $D$ the water diffusion coefficient, $C$ the water concentration, $t$ the time and $x$ the depth in the sample thickness. Water concentration $[\mathrm{W}]\left(\mathrm{mol} . \mathrm{L}^{-1}\right)$ was calculated from mass uptake at saturation (\% sat.), water molar mass $\left(18 \mathrm{~g} . \mathrm{mol}^{-1}\right)$ and TPU density $\left(1.19 \mathrm{~g} / \mathrm{cm}^{3}\right)$. Temperature dependence of D and \% sat. are plotted on Fig. 3, in Arrhenian type diagrams. D at $90{ }^{\circ} \mathrm{C}$ was not considered, the diffusion phenomenon being too fast at this temperature to be assessed using our method. D of TPU is 10-100 times higher than for epoxies [15,16] and in the same range as thermoset PU [17]. $\mathrm{D}$ and $\% \mathrm{~m}$ sat. values are in accordance with literature values on similar material [4,5]. The temperature dependence of $\% \mathrm{~m}$ sat. and D seems to obey the Arrhenius law for the temperature range considered here. Activation energies, determined as the slope of the best linear fit, are gathered in Table 2. Activation energies for D and $\%_{m}$ sat. are similar to values found in the literature [4,5]. Stabilization seems to have no effect on $\mathrm{D}, \% \mathrm{~m}$ sat. or activation energies.

Our kinetic model predicting lifetime is valid providing the hydrolysis kinetic is not governed by water diffusion. In other words, the characteristic time for hydrolysis $\tau_{\mathrm{H}}\left(\tau_{\mathrm{H}} \sim[\mathrm{E}] / \mathrm{k}_{\mathrm{Hu}}\right)$ has to be higher that the characteristic time for diffusion $\tau_{D}\left(\tau_{D} \sim L^{2} / D\right)$ with $\mathrm{L}$ sample thickness. In our experimental conditions we verify that $\tau_{\mathrm{H}} \gg \tau_{\mathrm{D}}$.

\subsection{Effect of ageing on water content}

Chemical ageing induced by hydrolysis can change water solubility in the polymers, as degradation products can have a different hydrophilicity from initial chemical groups [18]. It is thus of interest to follow water content change during ageing. Samples were immersed in water at $80^{\circ} \mathrm{C}$ for a definite period to cause ageing, then dried, and finally re-immersed in water at $25^{\circ} \mathrm{C}$ to assess water content at saturation. During immersion at $25^{\circ} \mathrm{C}$, ageing is considered very slow, thus water saturation $(24 \mathrm{~h})$ is reached without any chain scission. The effect of ageing on water content, expressed as mass uptake (\% sat.) or concentration (W) at saturation, is presented in Fig. 4, for unstabilized TPU. Water content increases with immersion time. This result will be further discussed in detail in the discussion section.

\subsection{Identification of hydrolytic degradation mechanisms}

\subsection{1. $N M R$}

Soft and hard block structure changes were investigated with ${ }^{1}$ H-NMR. Fig. 5 presents spectra of unstabilized TPU in its initial state and after ageing in water at $80^{\circ} \mathrm{C}$ for 19 days. Signals have been normalized with the area of peaks located at 7.05 and $7.35 \mathrm{ppm}$ (not shown), associated to protons 2 and 3, respectively.
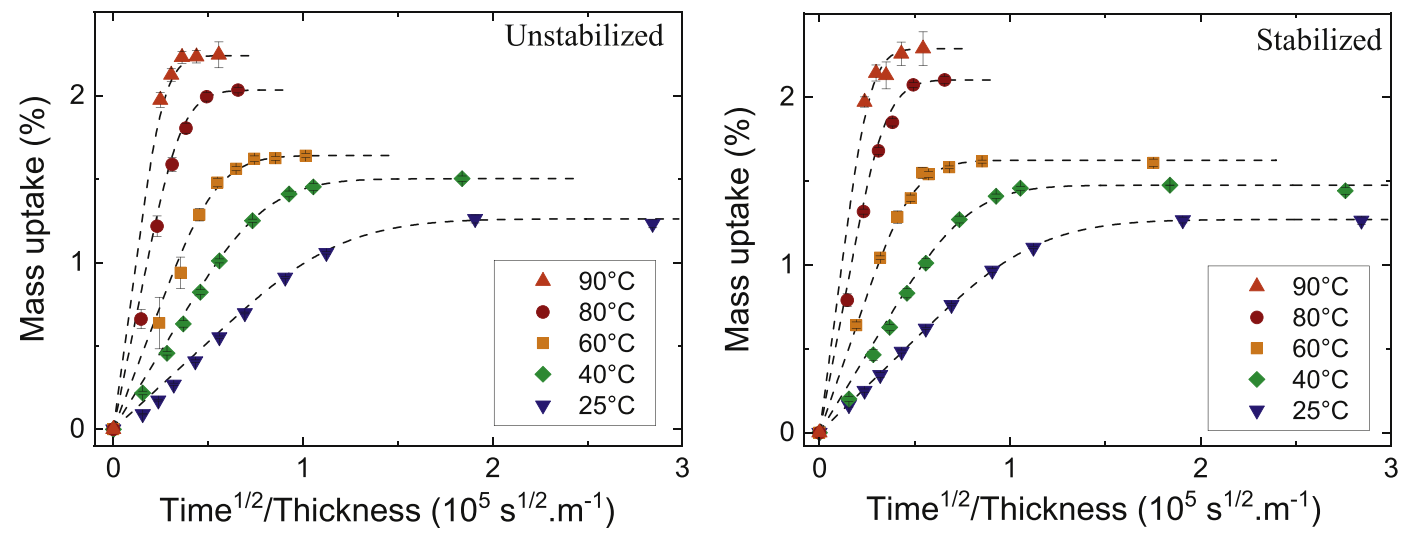

Fig. 2. Mass uptake in immersion at different temperatures, for unstabilized and stabilized TPUs. Corresponding 1D fickian law is plotted in dashed lines. 

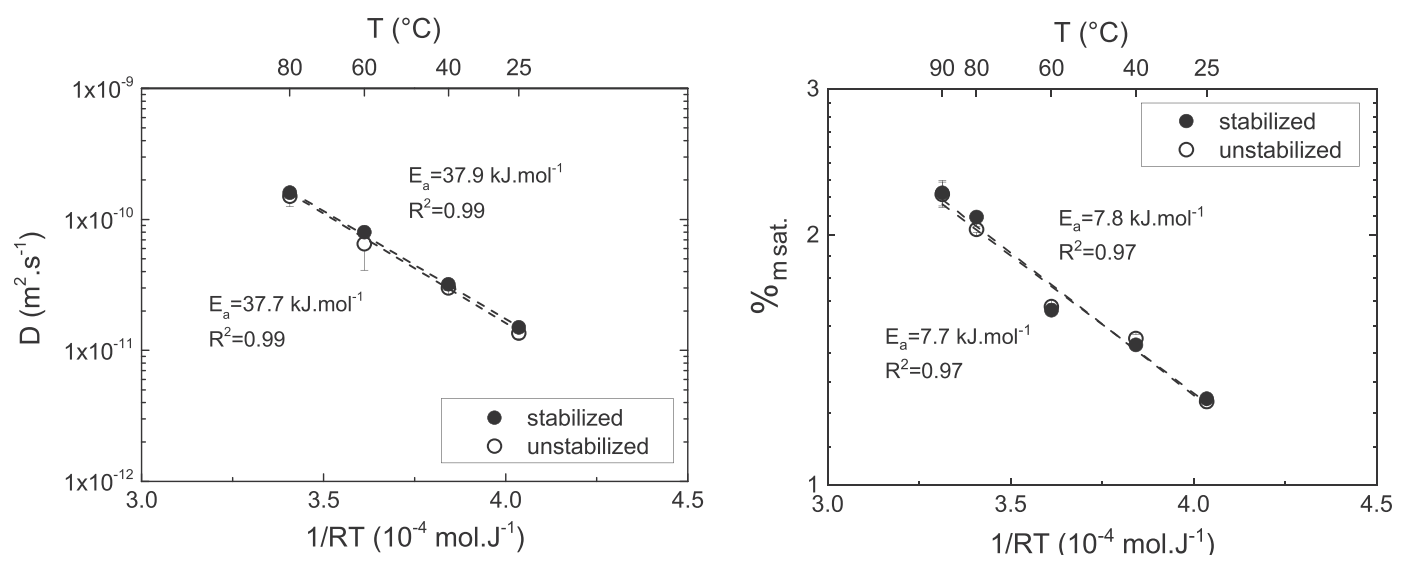

Fig. 3. Diffusion coefficient D and mass uptake at saturation $\% \mathrm{~m}$ sat. at different temperatures, for stabilized and unstabilized TPUs.

Table 2

Activation Energy $\mathrm{E}_{\mathrm{a}}\left(\mathrm{kJ} \cdot \mathrm{mol}^{-1}\right)$ of diffusion coefficient D and mass uptake at saturation $\%$ sat.

\begin{tabular}{lll}
\hline & Stab. TPU & Unstab. TPU \\
\hline D & 37.7 & 37.9 \\
\% sat. & 7.8 & 7.7 \\
\hline
\end{tabular}

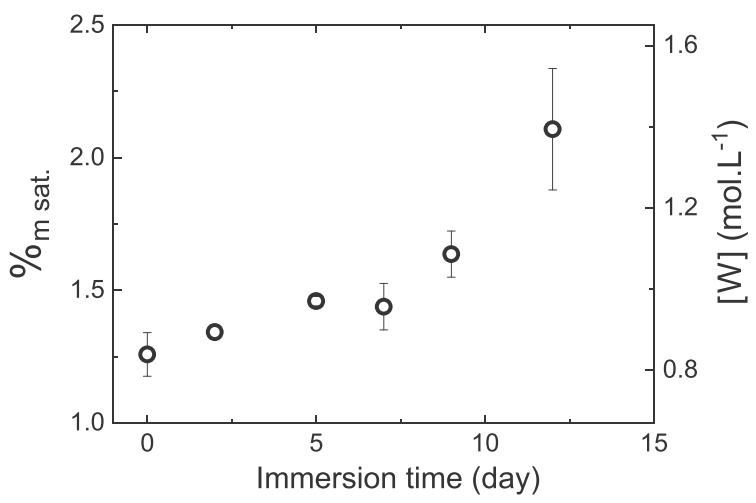

Fig. 4. Mass uptake at saturation $(\% \mathrm{~m}$ sat. $)$ and corresponding water concentration $[\mathrm{W}]$ as function of immersion time (unstabilized TPU, saturated at $25^{\circ} \mathrm{C}$ after ageing at $80^{\circ} \mathrm{C}$ followed by drying).

These peaks were attributed to phenyl groups, which are considered unchanged through ageing. Peaks at 1.60, 1.66, 2.28 and $4.05 \mathrm{ppm}$ (associated to protons $\mathrm{d}, \mathrm{b}, \mathrm{c}$ and a respectively) are attributed to the adipate (soft block). The area of these peaks decreases through ageing, which supports an ester hydrolysis hypothesis. The hard block's urethane group, associated to proton 1 with a peak at 8.70 (not shown), is not affected by ageing over the time range considered. This was expected, as the urethane group is reported to hydrolyse by an order of magnitude slower than ester group [6-8]. It was thus concluded that only adipate blocks are degraded. Several new small peaks are observed on the 19 days spectrum (at 1.51, 2.18 and $3.50 \mathrm{ppm}$ ). We suspected these peaks to be related to adipate block degradation products, but formal identification was not possible, mostly due to the weak intensity of these peaks. Considering the significant change in adipate peak area, peaks associated to degradation product were expected to be more intense. We supposed that small chains, formed through ageing, were released into the ageing water during immersion. To test this hypothesis, we performed ageing in closed environment, as opposed to immersion in continuously renewed water as

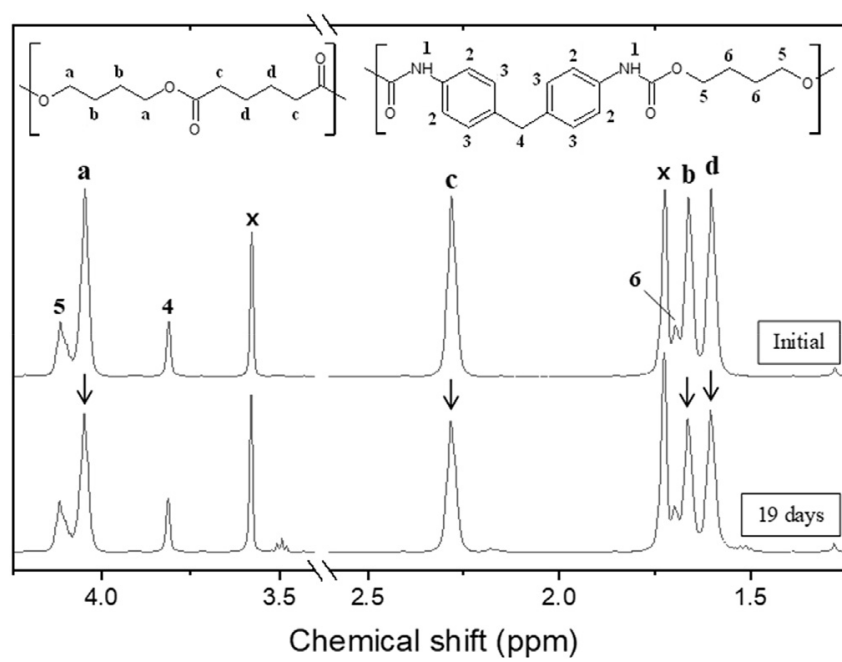

Fig. 5. ${ }^{1} \mathrm{H}-\mathrm{NMR}$ spectra of unstabilized TPU, solubilised in THF, in its initial state and after aging in water at $80^{\circ} \mathrm{C}$ for 19 days. Peaks are attributed to corresponding protons with letters for adipate soft block, and numbers for urethane hard block. Peaks identified with an $\mathrm{x}$ result from solvent response. Arrows indicate peaks change during ageing.

previously done. After advanced ageing, insoluble materials were filtered out, and water was evaporated. Residues left after evaporation were analysed with ${ }^{1} \mathrm{H}-\mathrm{NMR}$. Characteristic peaks of adipate degradation products were clearly identified. The presence of alcohol and carboxylic acid-based entities, products of the ester hydrolysis, was confirmed with 2D homo and heteronuclear analyses. Detail of the analysis procedure and residues $1 \mathrm{D}{ }^{1} \mathrm{H}-\mathrm{NMR}$ spectrum are presented in Annex A. Adipate degradation through ester group hydrolysis was thus confirmed with NMR.

\subsubsection{Macromolecular changes}

Chains scissions were characterized by measuring molar mass by GPC. Change in chromatograms during immersion is presented in Fig. 6. Chromatograms show no significant change in shape. They shift to higher retention volume, thus to lower molar mass. Average retention volume was used to calculate mass and number average molar masses, relative to the polystyrene reference. Polydispersity is around 2 through all immersion duration, for both TPUs and for all immersion temperatures (Fig. 6). As a result, chain scission mechanism can be considered as random and not diffusion limited. Chains scissions concentration after immersion time $\mathrm{t}$ is calculated according to Equation (3), with $\mathrm{M}_{\mathrm{n} 0}$ the initial number average 

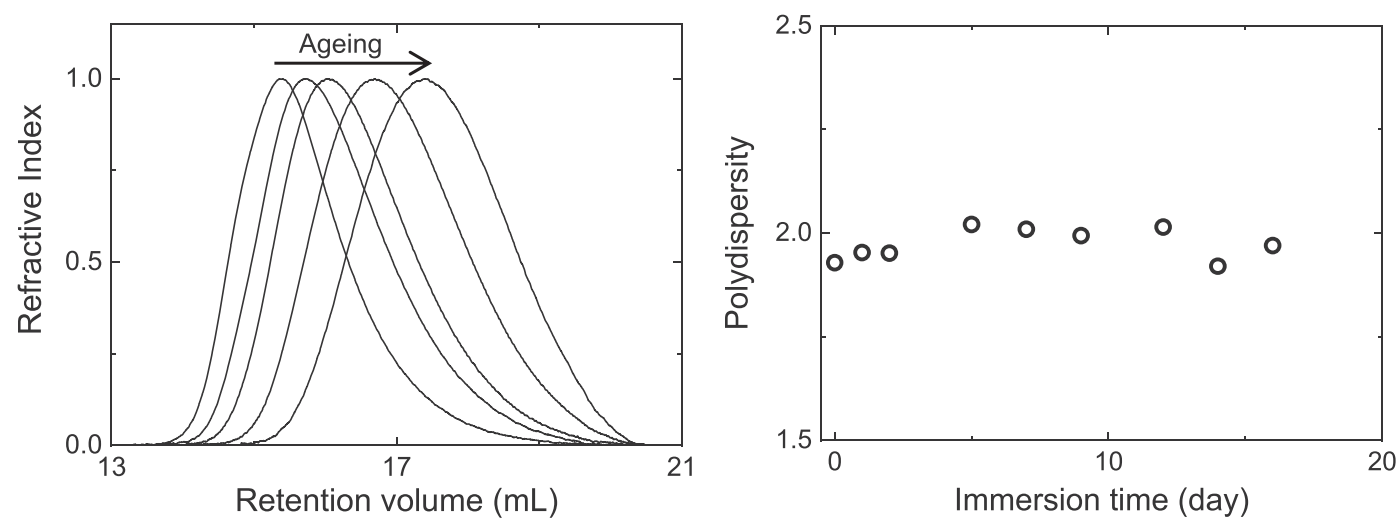

Fig. 6. Chromatograms from initial to 16 days immersion at $80^{\circ} \mathrm{C}$ for unstabilized TPU (left) and corresponding Polydispersity (right).

molar mass and $\mathrm{M}_{\mathrm{n}}(\mathrm{t})$ the number average molar mass after immersion time $t$. As immersion was performed in naturally oxygenated water, we checked the possibility that ester group consumption observed in NMR could also be due to an oxidative process. To investigate this hypothesis, exposure in air at the same temperature was performed. Samples showed no chains scissions over the time range considered here. Thus, it was concluded that the chains scissions observed were entirely due to hydrolysis of ester groups.

$\operatorname{Scissions}(t)=\frac{1}{M_{n}(t)}-\frac{1}{M_{n 0}}$

Fig. 7 presents chains scissions concentration increase with immersion time at $80^{\circ} \mathrm{C}$ for both TPUs. For unstabilized TPU, chains scissions show a strong increase from early immersion time. We can also note that the increase is accelerated with time. For the stabilized TPU, this acceleration is delayed. The delay is attributed to the anti-hydrolysis agent. After a stabilized period, i.e. once the agent is consumed, similar acceleration as for unstabilized TPU is observed. This behaviour will be discussed later through the proposed kinetic model.

\subsubsection{Crystallinity change}

Chains scissions effect on crystalline properties was investigated with WAXS. Crystalline diffraction peaks and amorphous scattering peaks were modelled with pseudo-Voigt functions, with a shape coefficient arbitrarily fixed at 0.8 and 0.2 respectively. Crystallinity Index $(\mathrm{CI})$ was calculated as the area under crystalline peaks over

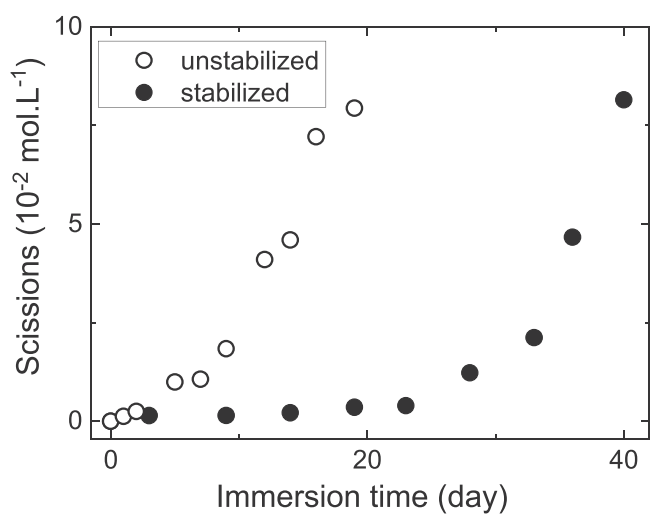

Fig. 7. Chains scissions concentration vs. immersion time at $80^{\circ} \mathrm{C}$ for unstabilized and stabilized TPUs. the total signal area. Diffractograms of unaged TPUs show a very broad signal with very few diffraction peaks, which we associated to very low crystallinity $(<1 \%)$. This low crystallinity can be explained by the presence of aromatic rings in hard blocks, hindering crystallization. During ageing, sharp peaks appear and increase. Associated crystallinity index increases, reaching over $15 \%$ for the most degraded samples (Fig. 8). No significant CI change is observed during the stabilized period. Scissions (Fig. 7) and CI seem to be closely correlated, which tends to support the idea that chemi-crystallization is occurring [19]. Crystallization occurs in the soft phase, as it is where scissions occur. DSC results are consistent with these observations. We observed that an endothermic peak associated to the soft phase appeared and increased during ageing, around $\mathrm{T}_{\mathrm{m}}=36^{\circ} \mathrm{C}$. The peak area increases at the same rate as IC's. Another peak is observable in the scans, around $\mathrm{T}_{\mathrm{m}}=140^{\circ} \mathrm{C}$. This peak is constant with ageing, it was associated to hard blocs (possibly h-bonding). We thus concluded that the increase in crystallinity is entirely due to crystallization of soft blocks.

\subsection{Temperature influence on kinetics}

Immersion at different temperatures was performed in order to study chains scissions kinetics and be able to extrapolate results to service temperature. Fig. 9 presents chains scissions for both unstabilized and stabilized TPUs, from 40 to $90^{\circ} \mathrm{C}$. If chains scissions kinetics are clearly temperature accelerated, it is noteworthy that similar behaviour are observed whatever the temperature of exposure. We can also note that very few chains scissions were

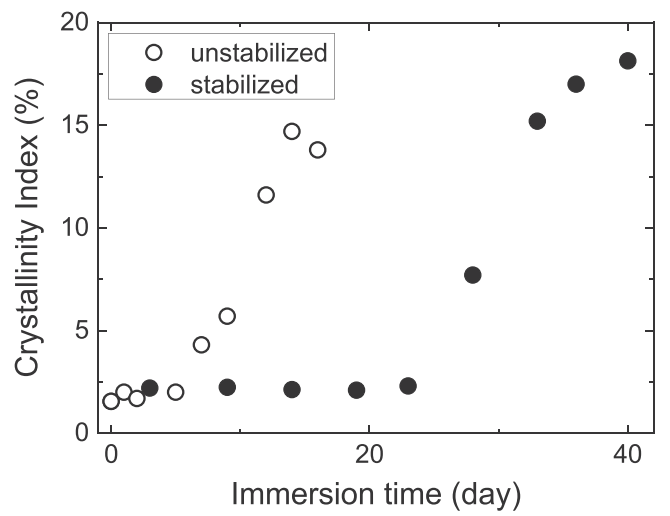

Fig. 8. Crystallinity Index determined by WAXS as a function of immersion time for both TPUs aged in water at $80^{\circ} \mathrm{C}$ 
detected even after 600 days of exposure at $40{ }^{\circ} \mathrm{C}$ for the stabilized TPU.

\subsection{Mechanical properties}

The effect of chains scissions on mechanical properties was investigated through uniaxial tensile tests. We focused here on elongation at break, since this property is often used by practitioners to characterise the embrittlement process in elastomers [20]. Elongation at break change for both TPUs at four temperatures are presented in Fig. 10.

Elongation at break shows a similar behaviour at every ageing temperatures. At first, a plateau is observed, for both TPUs. This plateau is longer for stabilized TPU, due to the stabilizer effect. Then, $\lambda_{b}$ drops, until a total loss of properties.

\section{Discussion and modelling}

\subsection{Modelling}

The purpose of this model is, first, to be able to describe scissions kinetics observed experimentally, and second, to be able to make predictions at other temperatures. On the typical time range necessary to total loss of mechanical properties, these scissions are only produced by the soft block ester group hydrolysis, as reported in the literature [6-8] and confirmed with NMR analyses (section 3.3.1). Random scissions were considered [21]. The hydrolysis opposite reaction, condensation, was ignored as usually done due to its negligible role on kinetics behaviour $[5,24]$.

\subsubsection{Model development}

The model developed in this paper is based on the one proposed by Brown et al. [12], who also studied the hydrolysis of TPU-ester containing carbodiimides. Three components constitute Brown's model: uncatalysed hydrolysis, acid-catalysed hydrolysis and carbodiimide reaction with carboxylic acid (Reaction 1 to 3 ). $\mathrm{k}_{\mathrm{Hu}}$ is defined as the uncatalysed hydrolysis rate constant, $\mathrm{k}_{\mathrm{Hc}}$ the catalysed hydrolysis rate constant and $\mathrm{k}_{\mathrm{s}}$ the stabilization rate constant.

Ester + Water $\stackrel{k_{H u}}{\rightarrow}$ Carbox. Acid + scission

(Reac. 1)

Ester + Water $^{k_{\mathrm{Hc}}(\text { Acid })}$ Carbox. Acid + scission

(Reac. 2)

Carbodiimide + Carbox. Acid $\stackrel{k_{s}}{\rightarrow}$ Inactive Product

(Reac. 3)

In Brown's model, carboxylic acid, formed by ester hydrolysis, is considered as the active substance catalysing the hydrolysis reaction. Indeed, in the differential equations, the catalysed component includes carboxylic acid concentration. Several studies share this approach [5,23]. In our work, we refined Brown's model by considering protons as the active substance catalysing ester hydrolysis, instead of carboxylic acid. This approach is closer to reality, and has been considered in other studies $[21,22,24] . \mathrm{H}^{+}$are present in water due to self-ionization of $\mathrm{H}_{2} \mathrm{O}$ molecules. In the case of TPU, the main source of protons comes from carboxylic acid $(\mathrm{COOH})$ dissociation, represented in Reaction 4 . The term autocatalysis is commonly used, as catalyst of the reaction is produced by the reaction itself. $K_{\mathrm{a}}$ is the acid dissociation equilibrium constant.

$\mathrm{COOH} \leftrightarrow \mathrm{H}^{+}+\mathrm{COO}^{-}$

(Reac. 4)

$\mathrm{H}^{+}$concentration or $\mathrm{pH}$ can indifferently be considered to characterise acidity, the former one was arbitrarily chosen. Considering an equilibrium state, proton concentration can be calculated as $\left[\mathrm{H}^{+}\right]=$ $\left(\mathrm{K}_{\mathrm{a}}[\mathrm{CA}]\right)^{1 / 2}$, with [CA] the carboxylic acid concentration $[23,25-27] . K_{a}$ dependence on temperature is based on values taken from Goldberg review [28]. The catalysed hydrolysis reaction rate $\mathrm{k}_{\mathrm{Hc}}$ was then considered directly proportional to the $\mathrm{H}+$ concentration (Equation (4)). $\alpha$ can be interpreted as a catalysis coefficient.

$k_{H c}=\alpha\left[H^{+}\right]=\alpha \sqrt{K_{a}[C A]}$

Monomeric carbodiimides react with acids to inhibit catalysis of ester hydrolysis. They are also known to react with water in acidic environment, but Brown and colleagues rejected this mechanism in their modelling, based on experimental observation. Also, comparison between characteristic carbodiimides reaction rate constants with acids [29] and with water [30] shows the first one prevails by approximately two orders of magnitude.

Water concentration change with ageing was observed in Fig. 4. Since water concentration has a significant effect on scissions kinetics, its change was taken into account in the model. A direct correlation was observed between water concentration [W] and scissions data within 12 days of exposure in Fig. 11. This observation supports the idea that change in water uptake at saturation is directly linked to change of hydrophilicity in the TPU [31]. Ester hydrolysis products, carboxylic acid and alcohol, are more hydrophilic, causing an increase in solubility with immersion time. According to Fig. 11, it is then possible to assess the slope $\gamma$ linking water concentration and scissions changes. Assuming this slope is not modified by the immersion temperature, the water concentration change can be included in the modelling through equation (8).
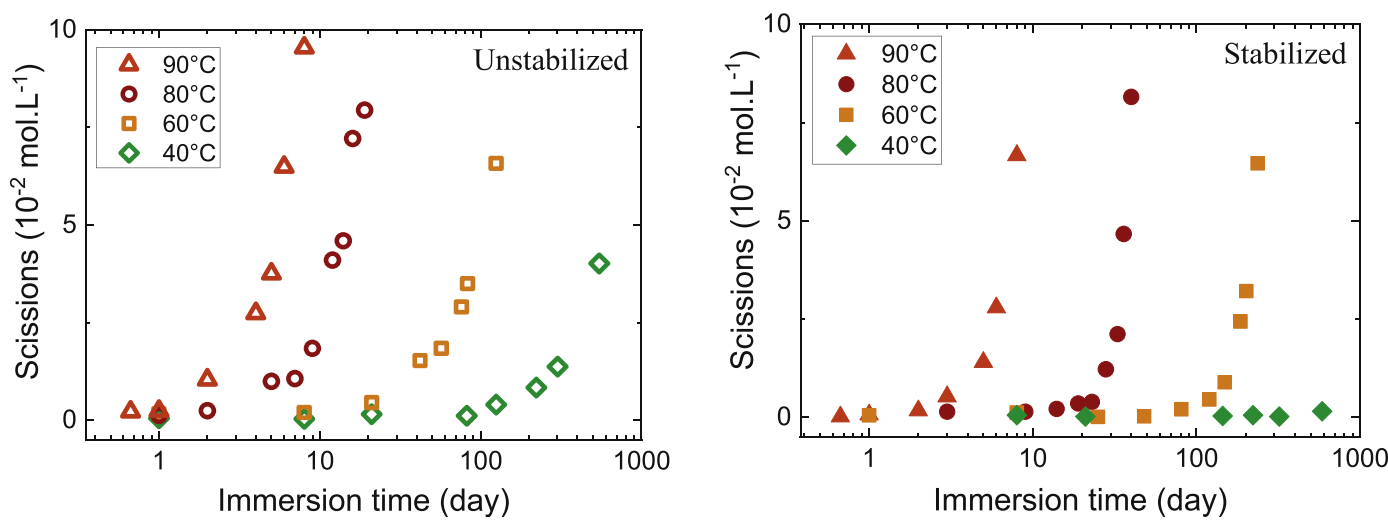

Fig. 9. Effect of temperature on chains scissions kinetics for unstabilized (left) and stabilized (right) TPUs. 

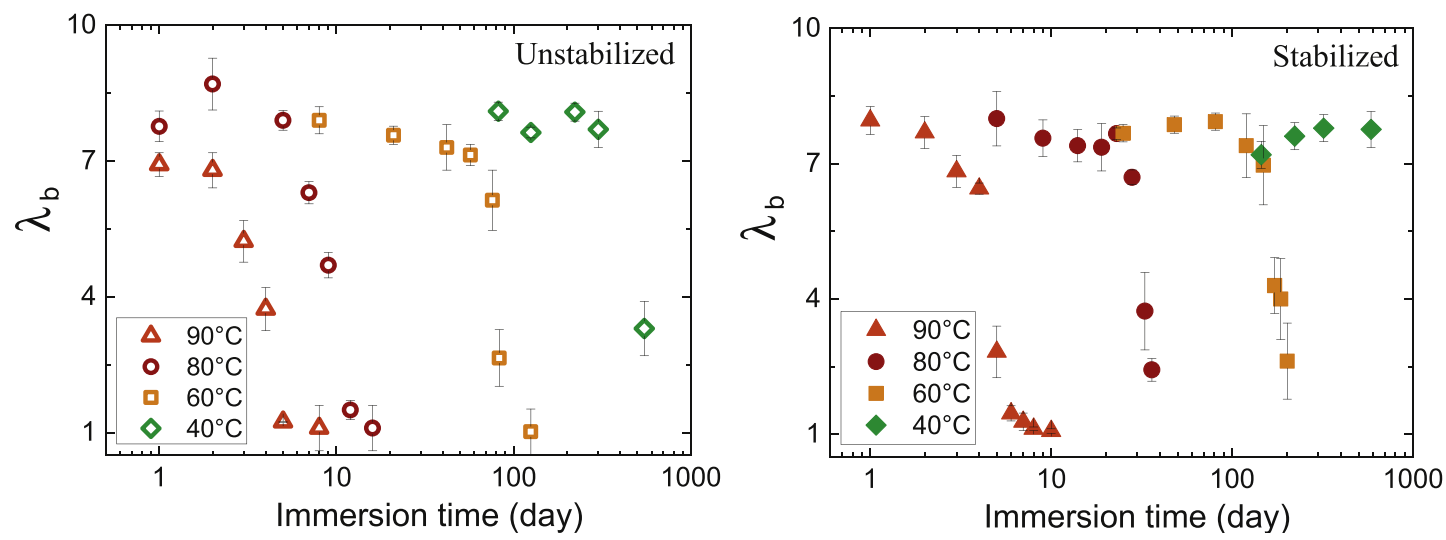

Fig. 10. Elongation at break as a function of immersion time from 40 to $90^{\circ} \mathrm{C}$ for unstabilized (left) and stabilized (right) TPUs.

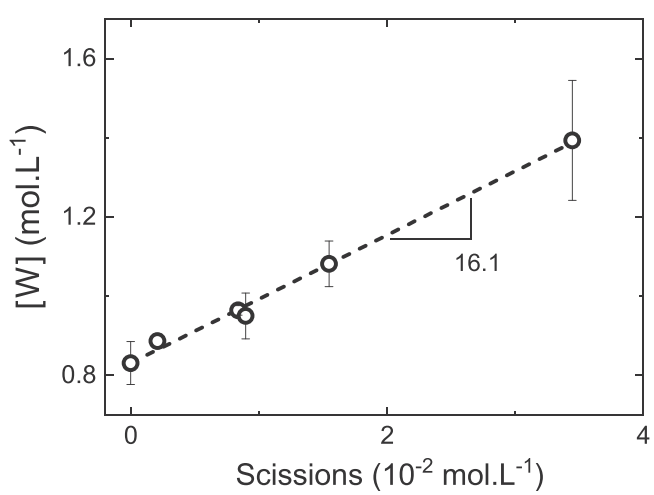

Fig. 11. Water concentration [W] change with scissions (unstabilized TPU during immersion at $\left.80^{\circ} \mathrm{C}\right)$.

Resulting differential equation system is represented through Equations (5)-(8), with [E], [W], [CA] and [Carb] corresponding to ester, water, carboxylic acid and carbodiimide concentrations, respectively.

$\frac{d[E]}{d t}=-\frac{d[\text { scissions }]}{d t}=-k_{H u}[E][W]-\alpha \sqrt{K_{a}[C A]}[E][W]$

$\frac{d[C A]}{d t}=k_{H u}[E][W]+\alpha \sqrt{K_{a}[C A]}[E][W]-k_{s}[C a r b][C A]$

$\frac{d[\text { Carb }]}{d t}=k_{S}[$ Carb $][C A]$

$\frac{d[W]}{d t}=\gamma \frac{d[\text { scissions }]}{d t}$

\subsubsection{Initial conditions}

Initial ester concentration $[E]_{0}$ was calculated considering NMR peak integration giving soft block/hard block ratio, and molar mass on initial sample. [E] $]_{0}$ was calculated as equal to $7.14 \mathrm{~mol} \mathrm{~L}^{-1}$, for both TPUs. Initial carbodiimide content is not disclosed by the supplier. Considering stabilized TPU scissions kinetics (Fig. 9), it was assumed that the onset of scissions acceleration corresponds to total consumption of carbodiimides. From the scissions concentration at this onset, an apparent stabilizer concentration [Carb $]_{0}$, only reacting with acids, was estimated at $7.10^{-3} \mathrm{~mol} \mathrm{~L}^{-1}$. Initial water concentration $[\mathrm{W}]_{0}$ was measured experimentally (Section 3.1). Initial carboxylic acid concentration $[\mathrm{CA}]_{0}$ was considered equal to 0 .

\subsubsection{Determination of parameters}

Model parameters were determined by curve fitting of experimental data, at every ageing temperature, with a rigorous step-bystep methodology. First, uncatalysed hydrolysis rate constant $\mathrm{k}_{\mathrm{Hu}}$ was determined (Fig. 12-Step 1). Considering the stabilized TPU, it was assumed that the first regime where very few scissions are observed is due to the inhibition of catalysis by carbodiimides. Once carbodiimides are consumed and catalysis starts, we observe a second regime, with a sharp scissions acceleration. $\mathrm{k}_{\mathrm{Hu}}$ was determined by curve fitting of the first regime. As catalysis is neglected on this period, scissions kinetics can be described by: $\mathrm{d}$ [scissions]/ $\mathrm{dt}=\mathrm{k}_{\mathrm{Hu}}[\mathrm{E}][\mathrm{W}]$. Being very few scissions while stabilizer is effective, $[E]$ and [W] change can be neglected, and $\mathrm{k}_{\mathrm{Hu}}$ can thus be assessed as the slope of the best linear fit between scissions and immersion time. At a given temperature, $\mathrm{k}_{\mathrm{Hu}}$ was considered equal for unstabilized and stabilized TPUs, as raw formulation is the same for both grades. Second, the catalysis coefficient $\alpha$ was determined (Fig. 12-Step 2). In that purpose, only the unstabilized TPU scissions were considered here. Only one regime is observed for this material, with scissions acceleration observed from start, due to catalysis. $\alpha$ was determined by solving the equation system presented is section 4.1, fixing $\mathrm{k}_{\mathrm{s}}=0$ in the case of unstabilized TPU. Like $\mathrm{k}_{\mathrm{Hu}}, \alpha$ was considered equal for unstabilized and stabilized TPUs. With $\mathrm{k}_{\mathrm{Hu}}$ and $\alpha$ known, it is possible to describe the unstabilized TPU scissions. Finally, the stabilization reaction rate constant $\mathrm{k}_{\mathrm{s}}$ was determined considering stabilized TPU scissions (Fig. 12-Step 3). $\mathrm{k}_{\mathrm{s}}$ was fitted so the onset of scissions acceleration predicted by the model matches the experimental data (approximately 23 days at $\left.80^{\circ} \mathrm{C}\right)$.

Predicted scissions are presented in Fig. 13, for ageing at $80^{\circ} \mathrm{C}$. Brown's model best fit was plotted for comparison. We observe that the model developed in the present study describes more accurately scissions kinetics, for both TPUs.

\subsubsection{Temperature dependence}

Time-temperature superposition of chains scissions considering all experimental temperatures is shown in Fig. 14. As an initial approach, we proposed to check out if the overall chains scissions kinetics follow an Arrhenian behaviour as it is often considered in literature [32-34]. In a second part, we assess the temperature dependence of the model constants. First, chains scissions data were superposed using a shift factor $\mathrm{a}_{\mathrm{T}}$, with $80^{\circ} \mathrm{C}$ as reference temperature (Fig. 14-a). $\mathrm{a}_{\mathrm{T}}$ dependence on temperature is presented 

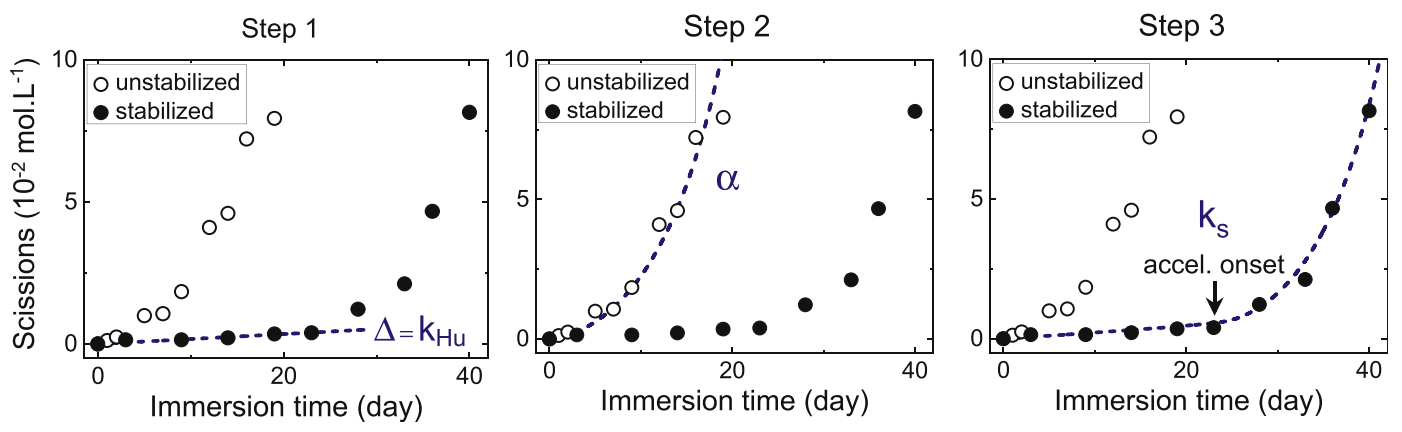

Fig. 12. Model constants determination by curve fitting of experimental scissions (ageing at $80^{\circ} \mathrm{C}$ ).

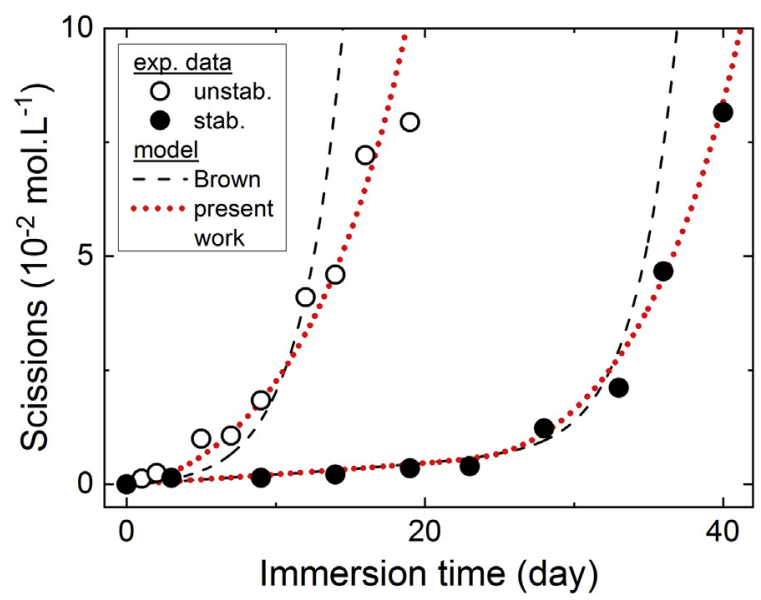

Fig. 13. Comparison of best fit of experimental data obtained with Brown's model and the model developed in the present work (ageing at $80^{\circ} \mathrm{C}$ ).

in Fig. 14-b a seems to have an Arrhenian behaviour for the unstabilized TPU $\left(\mathrm{R}^{2}=0.98\right)$, with an activation energy of $89 \mathrm{~kJ} \mathrm{~mol}^{-1}$. However, the Arrhenian behaviour for stabilized TPU is questionable $\left(R^{2}=0.94\right)$. Activation energy is significantly higher $\left(110 \mathrm{~kJ} \mathrm{~mol}^{-1}\right)$ for this grade. As ageing at $40^{\circ} \mathrm{C}$ was not advanced enough for proper superposition, data at this temperature were not considered for stabilized TPU. The potential non-Arrhenian behaviour of stabilized TPU chains scissions could be due to the stabilization reaction. In the hypothesis that stabilized TPU behaviour is indeed non-Arrhenian, using a kinetic model is then an appropriate alternative for extrapolation purpose.

Previously detailed methodology (section 4.1.3) was applied at every ageing temperature to determine $\mathrm{k}_{\mathrm{Hu}}, \alpha$ and $\mathrm{k}_{\mathrm{s}}$ constants. Experimental and modelled chains scissions are presented in Fig. 15. Even though ageing at $40^{\circ} \mathrm{C}$ is still in progress, existing data enabled us to determine $\mathrm{k}_{\mathrm{Hu}}$. Experimental behaviour is appropriately described at all temperatures, for stabilized and unstabilized TPUs.

\subsubsection{Discussion of constants}

Temperature dependence of model constants $\mathrm{k}_{\mathrm{Hu}}, \alpha$ and $\mathrm{k}_{\mathrm{s}}$ are presented in Fig. 16. The three properties exhibit an Arrhenian behaviour. Activation energies are reported in Table 3, with Brown's value for comparison. $\mathrm{k}_{\mathrm{Hu}}$ activation energy is higher than Brown's and other values in the literature [35]. $\alpha$ and $\mathrm{k}_{\mathrm{s}}$ activation energies are close to Brown's. Many factors affect these values, which are material and model dependent. Therefore, comparison between different studies has to be considered with caution.

\subsection{Structure-properties relationship}

As a linear polymer, we can expect TPU failure properties to be mainly governed by molar mass and/or crystallinity. Relationships between elongation at break and these two structural properties were considered. We propose to investigate the possibility to construct a master curve between elongation at break and these properties for all exposure conditions. The existence of a master curve will be, for us, the sign of a relevant structure-property relationship. Following this approach, Fig. 17 shows superposition of elongation at break as a function of molar mass at four temperatures, for both TPUs. A master curve is observed, independent of ageing temperature and presence of anti-hydrolysis agent. Starting from initial molar mass $\left(64.7 \mathrm{~kg} \mathrm{~mol}^{-1}\right.$ for unstabilized TPU and $84.3 \mathrm{~kg} \mathrm{~mol}^{-1}$ for stabilized TPU), the first decrease in molar mass has no effect on elongation at break. Then, a drop is observed. This behaviour is similar to a ductile-fragile transition as a function of molar mass, often observed in linear polymers [19] and for which we can associate a critical molar mass $\left(\mathrm{M}^{\prime}{ }_{\mathrm{c}}\right)$. This embrittlement molar mass can be approximately determined at $40 \mathrm{~kg} \mathrm{~mol}^{-1}$ in our case.

The elongation at break relationship with crystallinity index shows no master curve (Fig. 18). Results show a dependence of crystallinity on ageing temperature and presence of the stabilizer. Thus, crystallinity index appears not to be a proper criterion to follow ageing of the TPU.

\subsection{Lifetime prediction}

Since there is a doubt that scissions in immersed TPUs obey the Arrhenius law, we propose here to use our kinetic model to predict the lifetime of TPU-ester exposed to water. Knowing a combination of Arrhenian mechanisms having different activation energies can lead to a global non-Arrhenian behaviour, we can verify the capacity of our model to describe it. In this paper, we developed a hydrolytic kinetic model able to predict chains scissions at any temperature. We also highlighted a direct correlation between elongation at break and molar mass (equivalent to scissions concentration). Therefore, we are able to predict elongation at break change, and go further with lifetime prediction by considering an end-of-life criterion. Here, we considered the embrittlement molar mass $\left(\mathrm{M}_{\mathrm{c}}{ }_{\mathrm{c}}\right)$ as our criterion, as the mechanical property drops drastically when $\mathrm{M}_{\mathrm{n}}<\mathrm{M}^{\prime}$. Lifetime prediction is shown in Fig. 19.

Lifetime determined from experimental scissions is represented in scatter for comparison. It is noteworthy that our model can describe a non-Arrhenian behaviour, evidenced by a small curvature. As for comparison with Arrhenius prediction, we can witness that the discrepancy between lifetime at $10^{\circ} \mathrm{C}$ predicted with our model and predicted with an Arrhenian extrapolation based on data obtained at 80 and $90^{\circ} \mathrm{C}$ is higher than one decade. 

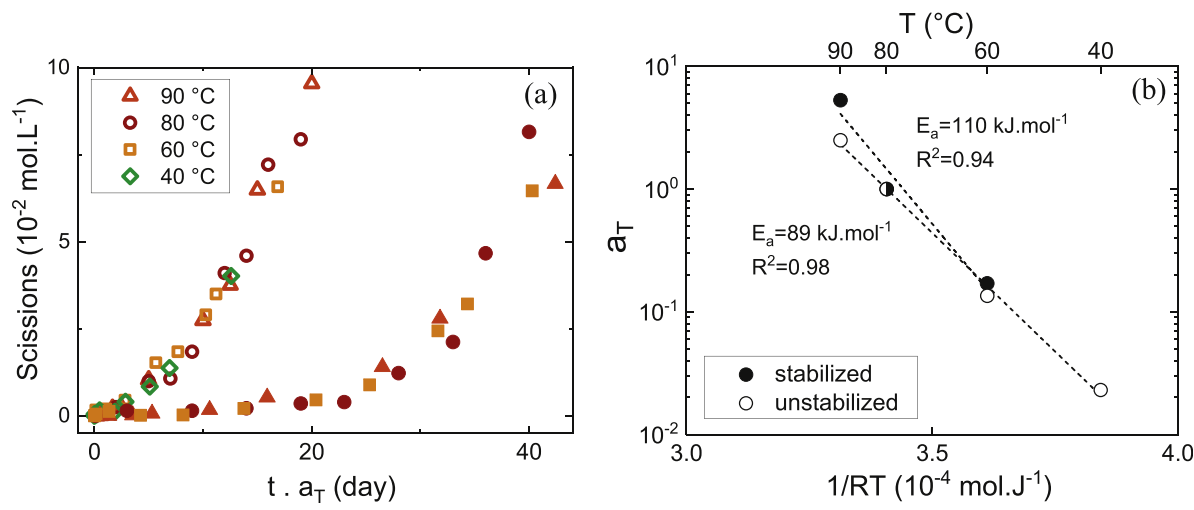

Fig. 14. (a) Time-temperature superposition of chains scissions, for unstabilized (hollow symbols) and stabilized (filled symbols) TPUs, and (b) temperature dependence of shift factor $\mathrm{a}_{\mathrm{T}}$
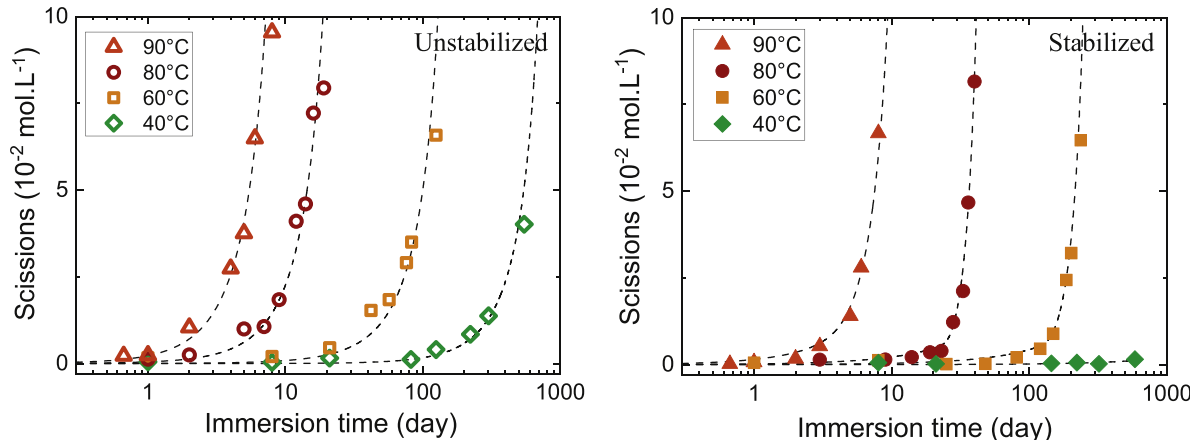

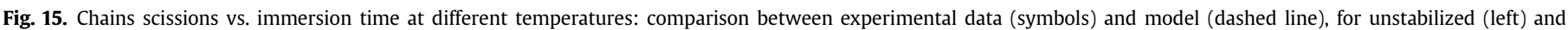
stabilized (right) TPUs.
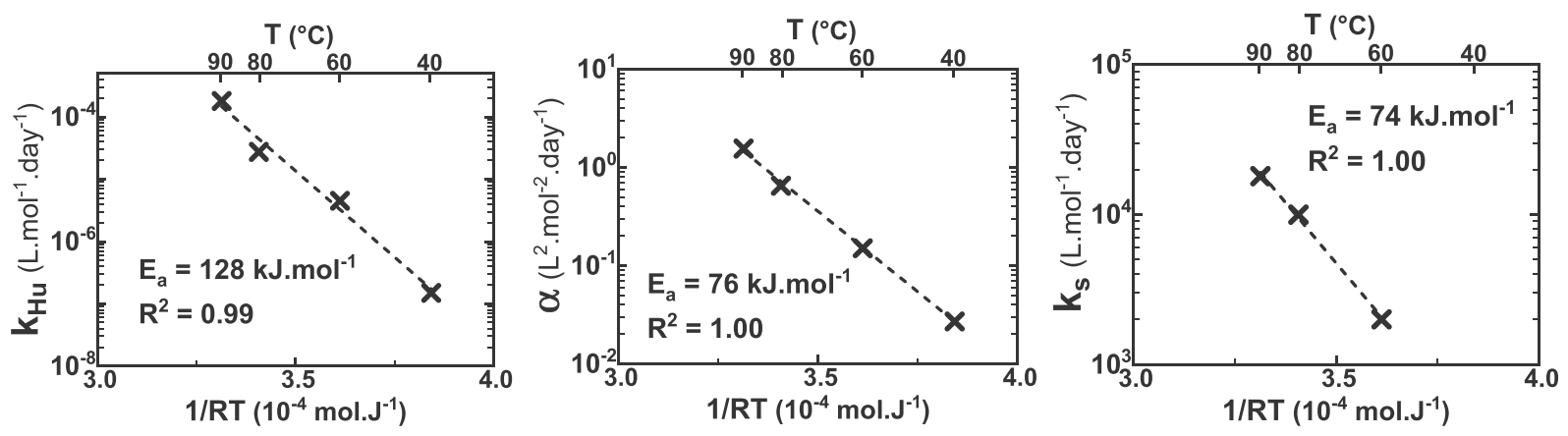

Fig. 16. Temperature dependence of uncatalysed hydrolysis rate constant $\mathrm{k}_{\mathrm{Hu}}$, catalysis constant $\alpha$ and stabilization reaction rate constant $\mathrm{k}_{\mathrm{s}}$

Table 3

Activation energies $\left(\mathrm{kJ} \cdot \mathrm{mol}^{-1}\right)$ associated to the different parameters.

\begin{tabular}{lll}
\hline & present study & Brown 1981 \\
\hline $\mathrm{k}_{\mathrm{Hu}}$ & 128 & 85 \\
$\alpha$ & 76 & 70 \\
$\mathrm{k}_{\mathrm{s}}$ & 74 & 55 \\
\hline
\end{tabular}

Additionally, this model can also be used to predict scissions kinetics in humid air, giving that the initial water concentration is known. As an example, the water content at $40^{\circ} \mathrm{C}$ and $50 \% \mathrm{RH}$ was measured $(\% \mathrm{~m}$ sat. $=0.54 \%)$ and the corresponding lifetime was predicted, represented in dotted lines in Fig. 19.

\section{Conclusion}

A hydrolytic kinetic model describing chains scissions kinetics in TPUs containing carbodiimide was successfully developed. Model inputs are associated to the material considered: initial ester group, stabilizer and water concentrations. Model constants were determined based experimental data. We showed that the proposed model can also be used for humid air ageing assessment. A master curve was observed for $\lambda_{b}-M_{n}$ relationship, independent of ageing temperature and presence of carbodiimide. We concluded that molar mass (or scissions concentration) is an appropriate property to assess TPUs ageing. Finally, lifetime prediction was realized. The capacity to predict non-Arrhenian behaviour was highlighted. 


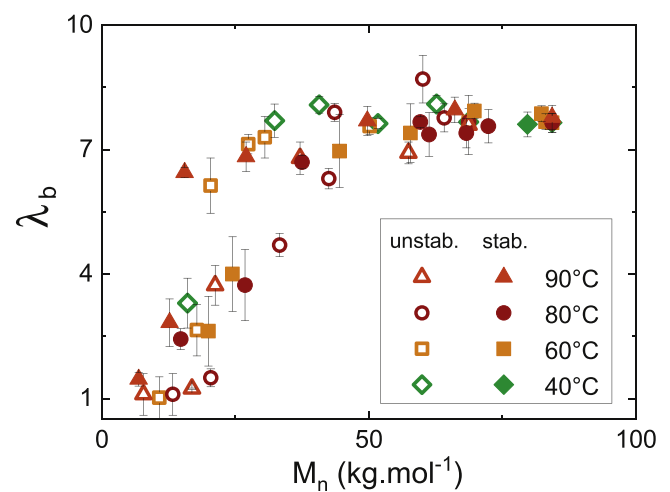

Fig. 17. Elongation at break as a function of $M_{n}$ for both TPUs, at four ageing temperatures.

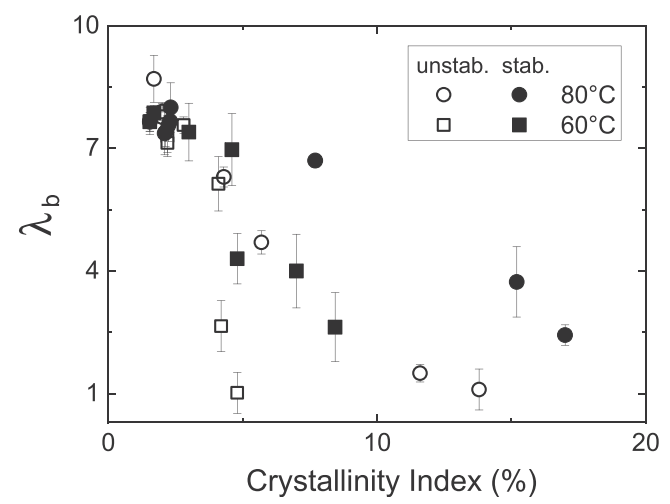

Fig. 18. Elongation at break in uniaxial tension as a function of crystallinity index for both TPUs aged in water at 60 and $80^{\circ} \mathrm{C}$.

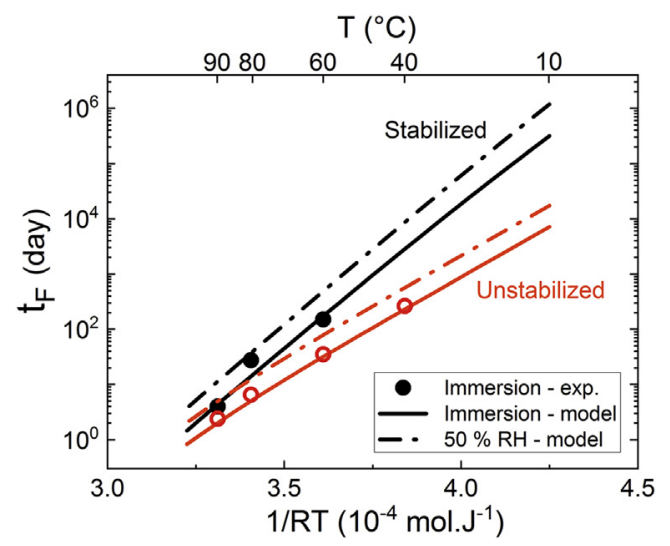

Fig. 19. Lifetime prediction of unstabilized and stabilized TPU-ester at two conditions: immersion and $50 \% \mathrm{RH}$.

\section{Declaration of competing interest}

None.

\section{Acknowledgements}

We gratefully acknowledge ANRT (CIFRE $N^{\circ}$ 2016/0796) for financial support, Thomas Bizien and all the Synchrtron Soleil team, as well as Matthieu Gervais, Nicolas Lacotte and Mickaël PremelCabic.

\section{Appendix A. Supplementary data}

Supplementary data to this article can be found online at https://doi.org/10.1016/j.polymdegradstab.2019.109002.

\section{Annexes}

Annex A

This annex details the procedure followed to identify adipate degradation product released in ageing water, by NMR analysis.

Closed circuit ageing was performed by putting approximately $30 \mathrm{~g}$ of unstabilized TPU in a $50 \mathrm{~mL}$ beaker, filled with deionised water. Ageing was performed by placing the beaker in an oven at $80^{\circ} \mathrm{C}$. Ageing was performed for 42 days, a time significantly longer than 19 days which is the longest exposure time in renewed water at this temperature, to ensure significant release of chains into the ageing water. Remaining samples were then extracted from water, and evaporation was performed. Solubilisation of residues was not perfect in THF. We suppose this was due to the presence of high polarity entities, which ester hydrolysis products are expected to be. In order to collect these polar chains, a liquid/liquid extraction using $\mathrm{CDCl}_{3}$ and $\mathrm{D}_{2} \mathrm{O}$ was performed. ${ }^{1} \mathrm{H}$-NMR analysis of the aqueous phase enabled adipate hydrolysis products to be identified: 1,4-butanediol and adipic acid (Fig. A-1). This observation was confirmed by $2 \mathrm{D}$ homo and heteronuclear analyses, where two sets of independent spin systems were found, associated to the alcohol and carboxylic acid-based entities.

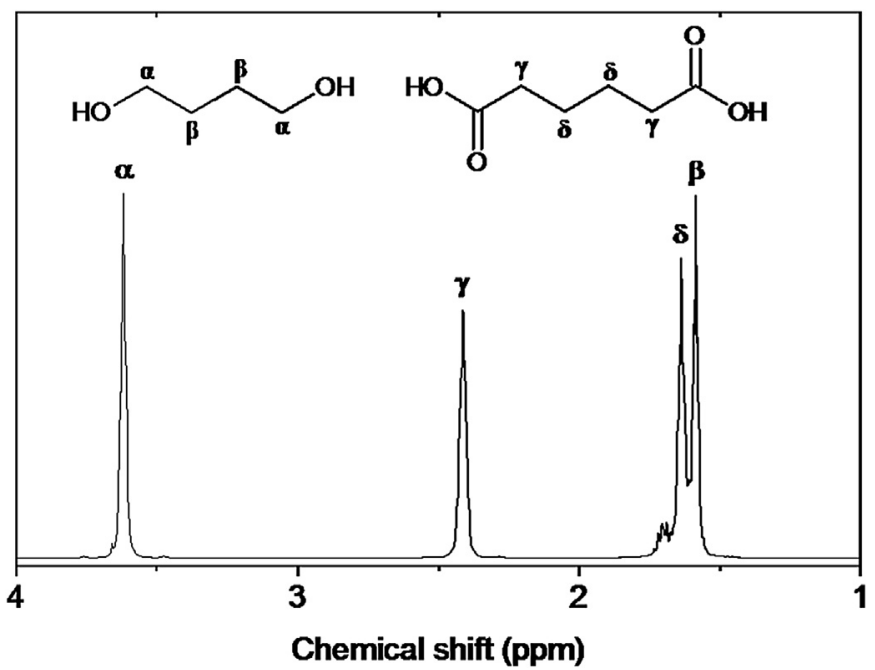

Fig. A.1. $1 \mathrm{D}{ }^{1} \mathrm{H}$ NMR spectrum of residues present in water after ageing of unstabilized TPU in water at $80^{\circ} \mathrm{C}$ for 42 days, in closed environment. Analysis was performed on $\mathrm{D}_{2} 0$ phase, after solubilisation in a $\mathrm{CDCl} 3 / \mathrm{D}_{2} 0$ mixed solvent. Peaks are identified to corresponding protons of adipate hydrolysis products: 1,4-butanediol and adipic acid.

\section{References}

[1] D.J. Buckwalter, J.M. Dennis, T.E. Long, Amide-containing segmented copolymers, Prog. Polym. Sci. 45 (Jun. 2015) 1-22.

[2] F. Xie, T. Zhang, P. Bryant, V. Kurusingal, J.M. Colwell, B. Laycock, Degradation and stabilization of polyurethane elastomers, Prog. Polym. Sci. 90 (Mar. 2019) 211-268.

[3] C. Prisacariu, Polyurethane Elastomers: from Morphology to Mechanical 
Aspects, Springer-Verlag, Wien, 2011.

[4] T. Pretsch, I. Jakob, W. Müller, Hydrolytic degradation and functional stability of a segmented shape memory poly(ester urethane), Polym. Degrad. Stab. 94 (1) (Jan. 2009) 61-73.

[5] C.M. Diaz, X. Gao, A. Robisson, M. Amarante, S.S. Zhu, Effect of hydrolytic degradation on the mechanical property of a thermoplastic polyether ester elastomer, Polym. Degrad. Stab. 155 (Sep. 2018) 35-42.

[6] L. Fambri, A. Penati, J. Kolarik, Synthesis and hydrolytic stability of mode poly(ester urethane ureas), Angew. Makromol. Chem. 228 (1) (Jun. 1995) 201-219.

[7] T.M. Chapman, Models for polyurethane hydrolysis under moderately acidic conditions: a comparative study of hydrolysis rates of urethanes, ureas, and amides, J. Polym. Sci. Part Polym. Chem. 27 (6) (May 1989) 1993-2005.

[8] D.G. Thompson, J.C. Osborn, E.M. Kober, J.R. Schoonover, Effects of hydrolysisinduced molecular weight changes on the phase separation of a polyester polyurethane, Polym. Degrad. Stab. 91 (12) (Dec. 2006) 3360-3370.

[9] C.S. Schollenberger, F.D. Stewart, Thermoplastic polyurethane hydrolysis stability, J. Elastoplastics 3 (1) (Jan. 1971) 28-56.

[10] D.W. Brown, R.E. Lowry, L.E. Smith, Kinetics of hydrolytic aging of polyester urethane elastomers, Macromolecules 13 (2) (Mar. 1980) 248-252.

[11] P. Stloukal, G. Jandikova, M. Koutny, V. Sedlařík, Carbodiimide additive to control hydrolytic stability and biodegradability of PLA, Polym. Test. 54 (Supplement C) (Sep. 2016) 19-28.

[12] D.W. Brown, R.E. Lowry, L.E. Smith, Hydrolytic degradation of polyester polyurethanes containing carbodiimides, Macromolecules 15 (Mar. 1982).

[13] T. Pretsch, W.W. Müller, Shape memory poly(ester urethane) with improved hydrolytic stability, Polym. Degrad. Stab. 95 (5) (May 2010) 880-888.

[14] C. Papaspyrides, A.W. Birley, Contribution of carboxyl end-groups to the hydrolytic instability of crosslinked polyesters, Polymer 19 (12) (Dec. 1978) 1474-1476.

[15] E. Linde, N.H. Giron, M.C. Celina, Water diffusion with temperature enabling predictions for sorption and transport behavior in thermoset materials, Polymer 153 (Sep. 2018) 653-667.

[16] A. Ilioni, P.-Y. Le Gac, C. Badulescu, D. Thévenet, P. Davies, Prediction of mechanical behaviour of a bulk epoxy adhesive in a marine environment, J. Adhes. 95 (1) (2019) 64-84.

[17] pierre yves le gac, D. Choqueuse, D. Melot, Description and modeling of polyurethane hydrolysis used as thermal insulation in oil offshore conditions, Polym. Test. 32 (Dec. 2013) 1588-1593.

[18] A. Launay, F. Thominette, J. Verdu, Hydrolysis of poly(ethylene terephthalate): a kinetic study, Polym. Degrad. Stab. 46 (3) (Jan. 1994) 319-324.

[19] B. Fayolle, E. Richaud, X. Colin, J. Verdu, Review: degradation-induced embrittlement in semi-crystalline polymers having their amorphous phase in rubbery state, J. Mater. Sci. 43 (Nov. 2008) 6999-7012.

[20] M.C. Celina, Review of polymer oxidation and its relationship with materials performance and lifetime prediction, Polym. Degrad. Stab. 98 (12) (Dec. 2013) $2419-2429$.

[21] X. Han, J. Pan, F. Buchanan, N. Weir, D. Farrar, 'Analysis of degradation data of poly(l-lactide-co-l,d-lactide) and poly(l-lactide) obtained at elevated and physiological temperatures using mathematical models', Acta Biomater. 6 (10) (Oct. 2010) 3882-3889.

[22] T. Bánsági, A. Taylor, Ester hydrolysis: conditions for acid autocatalysis and a kinetic switch, Tetrahedron 73 (May 2017).

[23] Lyu, et al., 'Kinetics and Time-Temperature equivalence of polymer degradation', Biomacromolecules 8 (7) (Jul. 2007) 2301-2310.

[24] P.I. Borovikov, et al., Model of aliphatic polyesters hydrolysis comprising water and oligomers diffusion, Polym. Degrad. Stab. 159 (Nov. 2018).

[25] C.M. Comisar, S.E. Hunter, A. Walton, P.E. Savage, Effect of pH on ether, ester and carbonate hydrolysis in high-temperature water, Ind. Eng. Chem. Res. 47 (3) (Feb. 2008) 577-584.

[26] A. Gleadall, J. Pan, M.-A. Kruft, M. Kellomäki, Degradation mechanisms of bioresorbable polyesters. Part 1. Effects of random scission, end scission and autocatalysis, Acta Biomater. 10 (5) (May 2014) 2223-2232.

[27] G.L. Siparsky, K.J. Voorhees, F. Miao, Hydrolysis of polylactic acid (PLA) and polycaprolactone (PCL) in aqueous acetonitrile solutions: autocatalysis, J. Environ. Polym. Degrad. 6 (1) (Jan. 1998) 31-41.

[28] R. Goldberg, N. Kishore, R. Lennen, Thermodynamic quantities for the ionization reactions of buffers, J. Phys, Chem. Ref Data 31 (Apr. 2002) 231-370.

[29] D.W. Brown, R.E. Lowry, L.E. Smith, Kinetics of the reaction between polyester acid and carbodiimide in dry polyester diols and in a polyester polyurethane, Macromolecules 14 (3) (May 1981) 659-663.

[30] O. Paula Lei, D.H. Lamb, R.K. Heller, A.G. Shannon, R. Ryall, P. Cash, 'Kinetic studies on the rate of hydrolysis of $\mathrm{N}$-ethyl- $\mathrm{N}^{\prime}$-(dimethylaminopropyl)carbodiimide in aqueous solutions using mass spectrometry and capillary electrophoresis', Anal. Biochem. 310 (1) (Nov. 2002) 122-124.

[31] A. Porfyris, et al., Accelerated ageing and hydrolytic stabilization of poly(lactic acid) (PLA) under humidity and temperature conditioning, Polym. Test. 68 (Jul. 2018) 315-332.

[32] J. Wise, K.T. Gillen, R.L. Clough, An ultrasensitive technique for testing the Arrhenius extrapolation assumption for thermally aged elastomers, Polym. Degrad. Stab. 49 (3) (Jan. 1995) 403-418.

[33] M. Deroiné, et al., Accelerated ageing and lifetime prediction of poly(3hydroxybutyrate-co-3-hydroxyvalerate) in distilled water, Polym. Test. 39 (Oct. 2014).

[34] N.S. Allen, M. Edge, M. Mohammadian, K. Jones, Hydrolytic degradation of poly(ethylene terephthalate): importance of chain scission versus crystallinity, Eur. Polym. J. 27 (12) (Jan. 1991) 1373-1378.

[35] E. Richaud, P. Gilormini, M. Coquillat, J. Verdu, Crosslink density changes during the hydrolysis of tridimensional polyesters, Macromol. Theory Simul. 23 (5) (2014) 320-330. 